\title{
AUTONOMIA PRIVADA E DISPOSIÇÃO DO PRÓPRIO CORPO: APOTEMNOFILIA EM DEBATE.
}

\section{PRIVATE AUTONOMY AND DISPOSAL OF OWN BODY: APOTEMNOPHILIA IN DEBATE.}

\author{
Marcelo de Mello Vieira ${ }^{1}$ \\ Bráulio Lopes de Assis ${ }^{2}$
}

\begin{abstract}
RESUMO
O presente artigo visa estudar questões que cada vez mais ganha relevância para o Direito nacional: o exercício da autonomia privada, a disposição do próprio corpo e os limites postos pelo ordenamento jurídico, especialmente nos casos de apotemnofilia. Primeiramente, foi abordada a autonomia privada, buscando-se trabalhar seu conceito atual, bem como delinear seus limites. Foram também trabalhados os direitos da personalidade, enfatizando o debate sobre a sua indisponibilidade. Posteriormente foi analisado especificamente um desses direitos o direito à integridade física ou corporal e expostas as possibilidades legais de sua disposição. Por fim, examinou-se a situação apotemnófilos, destacando suas especificidades em contraposição aos transexuais.
\end{abstract}

Palavras-chave: Autonomia privada, Integridade corporal, Apotemnofilia

\begin{abstract}
This article aims to study an issue that increasingly gains relevance in national law: the exercise of private autonomy, the disposal of one's own body and the corresponding limits set by the legal system, especially in apotemnophilia cases. Initially, we approached private autonomy, seeking to work on its current concept and outline its limits. This article also works on the rights of personality, emphasizing the debate on its unavailability. Then, one of such rights was specifically examined (the right to physical integrity, or bodily integrity), and the legal possibilities for its disposal were exposed. Finally, we examined the apotemnophiles' situation, highlighting its specific features as opposed to transsexuals.
\end{abstract}

Keywords: Private autonomy, Body integrity, Apotemnophilia

\footnotetext{
${ }^{1}$ Doutorando em Direito Privado pela Pontífícia Universidade Católica de Minas Gerais, PUC. Minas Gerias - MG, Brasil. E-mail: indexlaw.ojs@ hotmail.com

${ }^{2}$ Especialista em Direito Processual Aplicado pela Pontífícia Universidade Católica de Minas Gerais, PUC. Minas Gerais - MG, Brasil. E-mail: indexlaw.ojs@ hotmail.com
} 


\section{INTRODUÇÃO}

Mesmo depois de mais de vinte e cinco anos da promulgação da República Federativa do Brasil de 1988 (CRFB/1988), o Direito brasileiro ainda passa por um período de transformações e adequações. Essa nova ordem jurídica democrática fulcrada na dignidade da pessoa humana (CRFB/1988, art. $1^{\circ}$ III) exige que o Estado adote não só uma postura protecionista, mas que também permita que seus cidadãos desenvolvam suas individualidades, promovendo assim as potencialidades de cada um.

No Direito Privado, os direitos da personalidade ganham destaque, justamente por serem aqueles direitos que visam proteger e promover a personalidade de cada indivíduo. A autonomia da vontade, típica do Direito Civil negocial, ganha novas balizas e é substituída por uma ideia maior, autonomia privada, aplicável às relações existenciais. Ela não deve mais ser vista por uma perspectiva individual, mas sim exercida em um contexto relacional. Todavia, uma questão surge: a autonomia privada poderia ser fundamento para disposição dos direitos da personalidade?

O presente artigo visa debater essa questão a partir da análise da autonomia privada e do direito à integridade física. Nesse sentido, o trabalho abordará a autonomia no Estado Democrático de Direito, autonomia privada, fazendo a sua contraposição com a autonomia protegida pelo ordenamento jurídico nos paradigmas liberal e do Bem-Estar Social. Em um segundo momento, se analisará a noção dos direitos de personalidade trabalhando suas características principais. Posteriormente, trabalhar-se-á o direito à integridade física e a possibilidade de disposição desse direito, abordando-se também os princípios bioéticos. Partindo dos pontos trabalhados, se analisará a apotemnofilia, conhecida em pessoas denominadas wannabes, indivíduos que desejam a supressão de partes saudáveis de seu corpo por não se identificarem com elas.

\section{CONSIDERAÇÕES ACERCA DA AUTONOMIA PRIVADA}

A noção jurídica atual de autonomia é fruto de um processo que gradativamente agregou e posteriormente consolidou anseios sociais de determinados períodos históricos.

No período feudal, a sociedade era estamental, determinada pelo nascimento, não permitindo mobilidade social, ou seja, aquele cujos pais eram servos, também seria servo por toda sua vida, havendo, assim, pouco espaço para o exercício da autonomia individual. Além da rígida divisão de classes, o antigo regime era marcado pelos vários privilégios dados ao 
clero e à nobreza, o que fazia com que a classe servil fosse ainda mais explorada para custear as benesses dos outros estamentos.

Foram as revoluções burguesas do século XVIII que derrubaram o regime feudal e instalaram uma nova forma de Estado, que, baseado em ideais individualistas, promovia a valorização do ser humano frente ao mundo. Nesse contexto, o homem tornou-se o centro das sociedades, sendo todos seres humanos iguais, ainda que tal igualdade fosse meramente formal. O antropocentrismo desse novo Estado, também chamado Estado Liberal, deu contornos à autonomia: vez que se todos eram iguais, cada um poderia livremente escolher com quais pessoas gostaria de constituir obrigações jurídicas e sobre quais objetos versariam tais obrigações. Essa valorização da vontade individual foi denominada de autonomia da vontade.

Para Frederico Barbosa Gomes (2007), a noção de autonomia daquela época era profundamente influenciada pela filosofia de Kant, que, segundo o autor, é uma autonomia privada, haja vista que a conduta a ser adotada é promovida isoladamente por cada indivíduo, por meio do uso da razão, valendo-se, para tanto, do imperativo categórico 1 . A autonomia da vontade baseava-se apenas na justiça formal, e não na material propriamente dita (FARIA, 2007. p. 57). Dessa forma, sendo todos iguais, as vontades pessoais e o mercado regulariam a própria sociedade, cabendo ao Estado o papel de mero espectador que só interviria quando as avenças contrariassem a igualdade formal.

Ao invés de fortalecer as sociedades, a exacerbação da autonomia individual causou a exploração do homem pelo homem possuidor do capital, ocasionando profundas desigualdades. Paulo Bonavides (2007) destaca que naquele período havia graves arbitrariedades perpetradas por quem detinha o poder econômico, bem como trazia à classe menos abastada condições sub-humanas de vida, piores que aquelas já vividas no período medieval. Como resposta a tais desigualdades, o Estado passou a atuar na promoção de uma sociedade mais justa, não sendo mais apenas o garantidor de relações particulares, mas atuando diretamente na vida dos cidadãos, buscando a igualdade (material), o que não quer dizer que a autonomia da vontade tenha desaparecido (FARIA, 2007. p. 57), mas sim que ela sofreu profundas transformações, ganhando novos condicionantes como, por exemplo, a função social e a boa-fé. (PENALVA, 2009. p. 18).

\footnotetext{
${ }^{1}$ Trata-se em se buscar, dentro da filosofia Kantiana uma pretensão de universalidade. Neste sentido, afirma Kant que se "apenas segundo uma máxima tal que possas ao mesmo tempo querer que ela se torne lei universal." E também que age "como se a máxima da tua acção se devesse tornar, pela tua vontade, em lei universal da natureza." (KANT, p. 59, 1995).
} 
Surge então um novo Estado, o Estado do Bem-Estar Social, no qual a autonomia individual passou a sofrer limitações da vontade geral, ou seja, não há mais que se falar em autonomia da vontade individual isoladamente. Na verdade, busca-se a vontade coletiva como balizadora das vontades individuais, ou seja, há uma sobreposição do privado pelo público.

Segundo Gomes (2007), a ideia de autonomia pública foi baseada nas ideias de Rousseau, para o qual a autonomia dita pública é resultado da participação de todos por meio de um processo público de tomada de decisões. Assim sendo, a vontade geral é uma síntese da ideia de todos os participantes, e não a soma das vontades, isto é, essa vontade geral corresponderia ao bem comum de todos, não à vontade somada de cada um.

No entanto, ao longo do tempo, a busca da igualdade material refletida na preponderância do interesse público gerou um novo problema, o desrespeito às individualidades e escolhas pessoais. (VIEIRA, 2012, p. 1090). Assim, visando ao equilíbrio entre os ideais dos Estados Liberal e Social, surge o Estado Democrático de Direito, pretendendo garantir a liberdade individual e, ao mesmo tempo, o bem-estar da sociedade.

Instaurado no Brasil pela Constituição Federal de 1988 (CRFB/88), o Estado Democrático de Direito brasileiro tem como seus fundamentos a soberania, a cidadania, a dignidade da pessoa humana, os valores sociais do trabalho e da livre iniciativa e o pluralismo político (art. $1^{\circ}$ ). Com isso, o ordenamento jurídico nacional passou a focar no desenvolvimento de toda a sociedade e também de todos os cidadãos indistintamente, enfatizando a promoção da igualdade material, sem deixar de promover as potencialidades individuais.

Nesse paradigma se pressupõe uma participação da sociedade na construção de um novo sentido de autonomia, razão pela qual, após inúmeras batalhas no plano do Estado Liberal e Social, hoje, observa-se que a vontade individual como "máxima" para obtenção de seus fins restou-se mitigada, traduzindo-se em autonomia privada.

Frederico Gomes (2007) identifica que a autonomia no Estado Democrático de Direito se baseia no ideário de Habermas, que criticando Kant e Rousseau afirma que ambos cometeram o mesmo erro ao dar importância a apenas uma das faces da autonomia (Kant ressaltando o aspecto privado e Rousseau destacando o viés público) e trabalha o conceito de autonomia não separando os elementos privado e público, mas unindo-os.

Hoje, não se observa apenas a vontade individual como definidora do que pode ou não ser realizado (como no Estado Liberal). A autonomia privada deve ser concebida em um contexto relacional, com o reconhecimento recíproco dos sujeitos. Ainda, observa-se que ela deve acompanhar uma função social, não sendo correto pensar em uma atuação sem 
consequências sociais. Tem-se, portanto, nesse Estado Democrático de Direito, a definição de autonomia privada, que, diferentemente da ideia de autonomia de vontade, tem cunho objetivo, conforme as lições de Bruno Torquato e Danúbia Ferreira:

\footnotetext{
Embora representem o mesmo fenômeno, a autonomia da vontade traz uma carga do subjetivismo liberal, da perquirição da vontade interna, enquanto a autonomia privada encontra-se vinculada a um aspecto objetivo, melhor representante do discurso jurídico do Estado Democrático de Direito." (NAVES, RESENDE: 2007. p. 94)
}

Portanto, a definição de autonomia, hoje, caracteriza-se pela determinação de autonomia privada, sendo certo que tal autonomia não se vincula exclusivamente com interesses subjetivos do indivíduo, pois atende às necessidades de bem-estar da sociedade, evitando abusos por parte do indivíduo. Luciana Penalva define autonomia privada como aquela

\footnotetext{
(...) que legitima a ação do indivíduo, conformada à ordem pública e permeada pela dignidade da pessoa humana, ou, em outras palavras, a autonomia privada garante que os indivíduos persigam seus interesses individuais, sem olvidar da intersubjetividade, da interrelação entre autonomia pública e privada. (sic) (PENALVA, 2009, p. 22)
}

Deve-se ressaltar que, apesar do maior exemplo de autonomia se enquadrar nas relações contratuais, ou seja, no conteúdo patrimonial, deve se esclarecer que ela também atua em uma perspectiva existencial, que será abordada no presente trabalho, especialmente no tocante aos direitos de personalidade.

\section{DIREITOS DE PERSONALIDADE}

Assim como a autonomia privada, a proteção aos direitos de personalidade foi consagrada paulatinamente. Silma Berti (2000) destaca que já no medievo havia uma série de documentos legais que consagravam direitos que hoje são chamados de direitos da personalidade. No entanto, foi no século XX, em especial no pós $2^{\mathrm{a}}$ Guerra Mundial e em razão das atrocidades cometidas naquele período histórico, com grande influência do Direito alemão e francês, que se consolidou a proteção básica de tais direitos. (CHAVES; ROSENVALD, 2007, p. 106-107).

Para Adriano De Cupis (1950), os direitos da personalidade são todos aqueles que dão conteúdo à personalidade. Já Gilberto Jabur defende que "os direitos da personalidade são aqueles indispensáveis ao pleno desenvolvimento das virtudes biopsíquicas da pessoa” 
(JABUR, 2004, p.402). Para Gagliano e Pamplona Filho (2011), os direitos de personalidade são aqueles direitos que visam preservar os aspectos físicos, psíquicos e morais da pessoa. Logo, tais direitos existem para a defesa e, no novo contexto democrático, para a promoção de todos os aspectos da vida da própria pessoa, independentemente de o aspecto ser físico, psíquico, intelectual, entre outros ${ }^{2}$.

Embora consagrados internacionalmente e até assegurados pelo judiciário brasileiro desde a primeira metade do século $\mathrm{XX}^{3}$, os direitos da personalidade só foram expressamente tratados na legislação nacional no Código Civil de 2002 (CCB/2002), nos artigos 11 a 21.

$\mathrm{O}$ artigo 11 preconiza a intransmissibilidade e irrenunciabilidade dos direitos de personalidade, salvo em casos previstos em lei, e também prevê a impossibilidade desses direitos sofrerem limitações voluntárias ${ }^{4}$. Tais características advêm da necessidade de proteção pelo Estado de certos interesses individuais (MATTIELO, 2003, p. 31).

Conforme se observa, as limitações são de ordem legal, o que invariavelmente apenas admitiriam exceções quando assim disposto, como, por exemplo, no artigo 13 do CCB/2002, que trata da disposição do próprio corpo por necessidade médica.

No entanto, o Conselho da Justiça Federal na III Jornada de Direito Civil, em seu enunciado $\mathrm{n}^{\mathrm{o}} 4$ da I Jornada de Direito Civil, fixou o entendimento que: "O exercício dos direitos da personalidade pode sofrer limitação voluntária, desde que não seja permanente nem geral." No mesmo sentido, o enunciado $\mathrm{n}^{\mathrm{o}} 139$ do mesmo Conselho defende que: "Os direitos da personalidade podem sofrer limitações, ainda que não especificamente previstas em lei, não podendo ser exercidos com abuso de direito de seu titular, contrariamente à boa-fé objetiva e aos bons costumes." Tendo tais direitos íntima relação com a dignidade da pessoa humana e, como consequência, com a possibilidade de qualquer indivíduo desenvolver a própria individualidade, a atenuação da limitação total determinada pela literalidade do artigo 11 se mostra necessária. Nesse contexto, é extremamente salutar a interpretação das restrições à limitação voluntária, como proposta no enunciado $n^{\circ} 4$ acima mencionado, não podendo ser

\footnotetext{
${ }^{2}$ José de Oliveira Ascensão em seu artigo "Pessoa, Direitos Fundamentais e Direito da Personalidade" entende que os direitos fundamentais devem necessariamente ser previstos em lei, haja vista disposição da Constituição Portuguesa em seu art. 16/1. Porém, o referido autor entende que a legislação Civil não pode aspirar a proteção que a Constituição confere aos direitos, haja vista que o regime estabelecido no Código Civil não coincide com o regime da Constituição. Interessante ressaltar que o autor verifica que a compreensão de que haveria direitos fundamentais em lei infraconstitucional estenderia largamente a interpretação de dois institutos que não coincidem, quais sejam, os direitos fundamentais e os direitos de personalidade. (p.149 - 150).

${ }^{3}$ Silma Mendes Berti (2000) identifica uma sentença proferida em 1928 referente a captação não autorizada da imagem de Zezé Leone, mis Brasil de 1922, como a primeira decisão nacional que consagra a proteção de um direito da personalidade.
} 
${ }^{4}$ Além da intransmissibilidade e da irrenunciabilidade, César Fiuza (2007) considera os direitos da personalidade extrapatrimoniais. genéricos, absolutos e essenciais.

geral e nem permanente, uma vez que, do contrário, estaria se permitindo a renúncia desses direitos.

Já o artigo 12 do CCB/2002 prevê a possibilidade de se exigir a cessação de lesão ou de ameaça de violação ao direito de personalidade e de se demandar perdas e danos, além de outras sanções, como aquelas que por ventura possam ocorrer na esfera penal, além de estender esse direito à família, caso aquele que tiver seu direito violado já for falecido. Assim, o ordenamento, além de vedar a prática de disposição, limitação ou renúncia pelo titular do direito em casos determinados, assegura a tutela de tais direitos. (MATTIELO, 2003, p. 31).

Pode-se falar que os dois dispositivos do CCB/2002 mencionados visam dar concretude infraconstitucional ao princípio da dignidade da pessoa humana (CRFB/1988 - art. $1^{\mathrm{o}}$, III), sendo o artigo 12 uma verdadeira cláusula geral de proteção da personalidade. A existência de uma cláusula aberta é necessária, uma vez que as mudanças sociais muitas vezes alargam a proteção a tais direitos. Um dos exemplos é o direito à proteção da privacidade, previsto inclusive em meio virtual pela Lei 12.965/2014 (artigo $3^{\circ}$, II). A mesma lei disciplina a inviolabilidade do sigilo das comunicações pela internet, salvo por ordem judicial (artigo $7^{\circ}$, II), e a guarda e preservação da intimidade, privacidade e honra (artigo 10). Como se percebe, a Lei 12.965/2014, ao regular efetivamente a questão da privacidade, protegeu também a própria personalidade.

$\mathrm{O}$ CCB/2002 ainda enuncia a proteção a alguns direitos da personalidade (nome, honra, vida privada, vida e integridade física), constituindo tal rol meramente exemplificativo. Como já trabalhado, os direitos da personalidade visam proteger e promover o indivíduo enquanto ser humano, o que não poderia se restringir apenas a determinados direitos. Nesse contexto, se mostra novamente imprescindível a utilização da cláusula geral de proteção acima mencionada para a proteção desses direitos não enumerados na lei civil.

Dentre os direitos enunciados pelo $\mathrm{CCB} / 2002$, o direito à integridade física merece uma análise mais detida, em razão de questionamentos a sua proteção.

\section{DIREITO DA PERSONALIDADE À INTEGRIDADE FÍSICA E OS PRINCÍPIOS BIOÉTICOS}

A proteção à integridade física é verificada com a proteção do corpo humano desde a concepção, com medidas protetivas que asseguram a sua inviolabilidade até mesmo de pessoas falecidas. A proteção à integridade física ainda goza de amparo do Código Penal que, 
em seus artigos 121 a 128, tratam da proteção ora mencionada. (FARIAS, ROSENVALD, 2007, p.118).

Pablo Stolze e Rodolfo Pamplona (2011) estendem a proteção dada à integridade física para a proteção intelectual. Na mesma linha, o enunciado $\mathrm{n}^{\circ} 6$ da Jornada de Direito Civil entendeu que a exigência médica também diz respeito ao bem-estar psíquico. Para Ingo Wolfgang Sarlet (2012), a proteção à integridade física abarca a proteção à integridade externa, ao corpóreo e à integridade interna como esfera psíquica ${ }^{5}$.

A integridade física tem relevante proteção jurídica, principalmente em uma época em que os avanços tecnológicos e medicinais propiciam uma infinidade de meios de alteração da estrutura física, seja de forma benéfica ou maléfica.

Conforme já exposto acima, o corpo é inalienável, não obstante a possibilidade de disposição de partes do corpo conforme previsto no artigo 13 do CCB/2002, desde que ocorra por requisição médica, sem que ocorra mutilação ou diminuição da integridade ou que seja contrário aos bons costumes.

Sobre a parte final do artigo 13, no que se refere aos bons costumes, uma crítica deve ser feita. Tal conceito é um termo aberto, não podendo ser utilizado como um limitador efetivo, haja vista a pluralidade da sociedade atual. Para Konder (2003, p. 64), o termo bons costumes é incompatível com a ordem constitucional vigente, justamente pela pluralidade e tolerância necessária nos dias atuais, devendo o legislador acrescentar termos precisos para direitos efetivamente previstos no texto constitucional.

A regulamentação para dispor o corpo em vida se deu pela Lei $n^{\circ} 9.434 / 1997$, alterada pela Lei 10.211/2001, tendo sido estabelecido que a disposição de partes do corpo pode acontecer quando a pessoa for juridicamente capaz, ocorrendo de forma gratuita, para fins terapêuticos ou transplante em parentes consanguíneos até quarto grau ou outra pessoa, desde que com autorização judicial. Tal previsão vem ao encontro do que dispõe a CRFB/1988 em seu art.199, $₫ 4^{\circ}$, visando facilitar os transplantes no Brasil.

Não se pode deixar de mencionar que a Lei 10.211/2001 contém outras condicionantes além das citadas, são elas: a existência de órgãos duplos e que a retirada da parte/órgão não traga risco de vida, não impeça as aptidões vitais e saúde mental ou que não cause mutilação, devendo ainda corresponder a uma necessidade terapêutica indispensável a aquele que

\footnotetext{
5 O preâmbulo da Constituição da Organização Mundial de Saúde (OMS) dispõe: A saúde é um estado de completo bem-estar físico, mental e social, e não consiste apenas na ausência de doença ou de enfermidade. Gozar do melhor estado de saúde que é possível atingir constitui um dos direitos fundamentais de todo o ser humano, sem distinção de raça, de religião, de credo político, de condição econômica ou social.

Acesso em: http://www.direitoshumanos.usp.br/index.php/OMS-Organiza\%C3\%A7\%C3\%A3o-Mundial-da-

Sa\%C3\%BAde/constituicao-da-organizacao-mundial-da-saude-omswho.html
} 
receberá o órgão. As limitações impostas, mesmo que de forma terapêutica, devem ser sempre observadas dentro da legalidade, sob pena de incorrer em infração à necessidade de proteção imposta pelos direitos de personalidade. Nesses casos, o consentimento do receptor é indispensável, bem como a comunicação ao Ministério Público Estadual, o que se faz com o intuito de evitar possíveis vendas de órgãos, e, em casos em que o doador for incapaz, para preservar-lhe o direito. (CHAVES; ROSENVALD, 2007, p. 120).

Observa-se, portanto, que os transplantes de órgãos e tecidos, apesar de possuírem uma série de limitações, são admitidos no Direito pátrio, bem como recebem incentivo em razão de sua natureza humanitária e social, tendo a necessária regulamentação infraconstitucional para tanto.

A Lei 9.434/1997 também delimitou a atuação das instituições de saúde para remoção e transplante de órgãos, haja vista serem as únicas que, licitamente, podem realizar tal atendimento, conforme se depreende do artigo $2^{\circ}$ da referida lei. A lei de transplantes trata ainda da questão referente à autorização dos familiares para retirada de órgãos, quando post mortem $^{6}$, afastando assim o antigo entendimento acerca da autorização presumida, que, ressalte-se, causou transtornos em casos que o paciente recuperou a consciência quando iria ocorrer a cirurgia de retirada de órgãos ${ }^{7}$. Claramente, tais dispositivos legais visam dar efetividade à questão da dignidade humana e a proteção à integridade física post mortem, considerando em especial a questão do respeito à memória do de cujus. (GAGLIANO, PAMPLONA FILHO, 2011, p. 206) ${ }^{8}$.

Toda atividade relacionada com atos de disposição e dever de cuidado com o ser humano em sua integridade física é balizado pelos princípios bioéticos, sendo eles: a autonomia, que traduz a ideia de respeito ao paciente; a beneficência, que traz à tona o fato de apenas beneficiar o enfermo; a não maleficência, em que não deve haver dano intencional ao paciente; e a justiça, que traduz a divisão imparcial de recursos. Tais princípios são diretrizes

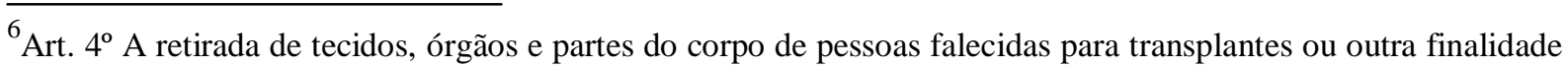
terapêutica, dependerá da autorização do cônjuge ou parente, maior de idade, obedecida a linha sucessória, reta ou colateral, até o segundo grau inclusive, firmada em documento subscrito por duas testemunhas presentes à verificação da morte.

Art. $5^{\circ}$ A remoção post mortem de tecidos, órgãos ou partes do corpo de pessoa juridicamente incapaz poderá ser feita desde que permitida expressamente por ambos os pais, ou por seus responsáveis legais.

7 "Célebre é o caso de Jason Arthur Rae, que, 'dado como morto ao sofrer, em 14 de julho de 1973, uma grave lesão cerebral numa piscina, nos Estados Unidos, tendo sua mãe anuído no transplante de rins e fígado, respondeu aos estímulos de dor quando os médicos se preparavam para a operação, recobrando a respiração 45 minutos depois'" (GAGLIANO, PAMPLONA FILHO, 2011, p. 207).

${ }^{8}$ Visando também garantir a universalização da saúde e também a igualdade de chances de se receber o órgão almejado (arts. $3^{\circ}, 5^{\circ}$ e 196 da CRFB/1988), a Lei de Transplantes criou a lista única de espera em seu art. $10^{\circ}$, o que permite não favorecer conhecidos em detrimento de quem está na fila de espera. Ressalte-se que quando se trata de parente consanguíneo até quarto grau, o doador juridicamente capaz pode escolher que seja destinado à ele. (CHAVES; ROSENVALD, 2007, p. 120).
} 
ticas básicas que devem nortear todo trabalho que se dê junto a seres humanos, sejam experimentos ou a própria manutenção da vida. (DINIZ, 2011, p. 38).

O primeiro princípio (autonomia) traduz a ideia de respeito do profissional da saúde à vontade do paciente. Este possui projetos de vida, pontos de vista e opiniões que devem ser respeitadas, sendo certo que tal princípio serve também de base para fundamentação da dignidade humana. Deve-se ressaltar que esse princípio é o que favorece a relação médico paciente quando em tratamento, uma vez que o respeito à condição do paciente, concedendo a ele as devidas informações para conscientizá-lo do seu quadro, favorece o tratamento, bem como desenvolve uma relação de confiança para realização de diagnósticos e dos procedimentos devidos para o tratamento. (LOCH, 2002, p. 04).

Já o princípio da beneficência baseia-se na tradição hipocrática ${ }^{9}$, que visa sempre beneficiar o enfermo. Tal princípio significa que é dever do profissional da saúde agir em benefício do paciente, sendo essa ação uma obrigação moral. Esse princípio ainda traz a ideia de não apenas fazer o bem momentaneamente, mas, ainda, prevenir e remover o dano, bem como manter o bem-estar físico, emocional e mental do paciente. Ele impõe ainda ao profissional de saúde o dever de se abster de praticar procedimentos de eficácia duvidosa (NAVES, SÁ, 2011, p. 33). Tal atuação deve ocorrer de forma positiva, avaliando benefícios, riscos e custos. (LOCH, 2002, p.03).

No tocante ao princípio da não maleficência, Maria Helena Diniz (2011) sucintamente dispõe: "O princípio da não maleficência é um desdobramento do da beneficência, por conter a obrigação de não acarretar dano intencional e por derivar da máxima da ética médica: primum ninnocere". Para Loch (2002), tal princípio é fundamental para atuação médica, uma vez que em alguns casos é difícil separar o risco do dano da atuação ética esperada, já que todas as intervenções médicas têm um risco, mesmo que pequeno, como o sangramento para retirada de sangue.

Por fim, o princípio da justiça traz a ideia da imparcialidade na distribuição de riscos e benefícios disponíveis no âmbito da prática médica (DINIZ, 2011, p. 40), bem como traduz a ideia de distribuição equitativa dos bens e recursos existentes para a atuação médica. (LOCH, 2002, p.05). Para Naves e Sá (2011), esse princípio busca maximizar os benefícios com o mínimo de custo possível, devendo ser contabilizado nesses custos tanto o valor financeiro quanto sociais, emocionais e físicos.

\footnotetext{
9 [...] o profissional da saúde, em particular o médico, só pode usar o tratamento para o bem do enfermo, segundo sua capacidade e juízo, e nunca para fazer o mal ou praticar a injustiça. (DINIZ, p.39, 2011).
} 
Pelo todo trabalhado até aqui, nota-se que a disposição de partes do corpo pelo próprio titular do direito à integridade física é exceção, devendo o profissional de saúde agir estritamente dentro dos parâmetros principiológicos da bioética. No entanto, uma questão parece ganhar destaque nos dias de hoje: poderia a autonomia privada ser um fundamento legítimo para que alguém suprimisse partes do seu próprio corpo?

\section{REFLEXÕES SOBRE OS WANNABES}

Por mais surpreendente que pareça, existe um grupo de pessoas, os apotemnófilos, ou wannabes, que deseja suprimir uma parte do seu próprio corpo ${ }^{10}$. Eles são indivíduos que, embora tenham o corpo saudável, acreditam que uma determinada parte dele, geralmente um membro, não corresponde com a imagem que eles mesmos possuem do seu próprio corpo (PORRES; RODRIGUEZ, 2013, p. 38). Para Konder (2003) seria como se o físico não correspondesse com a identidade corporal daquela pessoa.

A apotemnofilia é uma body integrity identity disorder (BIID) que causa grandes transtornos aos seus portadores, pois os wannabes acreditam que somente a amputação daquela parte do corpo que não identificam como parte de si poderá fazer com que se reconciliem com sua imagem física.

Diante da similaridade com o transtorno de identidade sexual (transexualismo), Menezes e Gonçalves (2012) defendem que deveria se dar à apotemnofilia o mesmo tratamento dado aos distúrbios de gênero. Elas explicam que em casos de transexualismo, após o diagnóstico de desvio permanente de identidade sexual com rejeição do fenótipo e tendência ao suicídio ou à automutilação, a pessoa permanece por pelo menos dois anos sob acompanhamento com o fito de se averiguar se o distúrbio é permanente. Somente depois de assegurado que aquela condição é consistente e duradoura, é permitida a realização da cirurgia. As autoras concluem que

\footnotetext{
Assim, a proposta mais consentânea com a dignidade da pessoa com body integrity identity disorder (BIID) seria, primeiramente, seu acompanhamento e tratamento, sendo permitida a amputação apenas na extrema circunstância em que o bem estar psicofísico não possa ser assegurado de outra forma. (MENEZES, GONÇALVES, 2012, p. 50-51).
}

\footnotetext{
${ }^{10}$ Tanto Carlos Konder (2003) quanto María Porres e Ana Rodríguez (2013) observam que a internet tem sido usada pelos wannabes para se reunirem e trocarem informações proporcionando uma maior visibilidade a esse grupo de pessoas.
} 
Embora parecidos, o BIID apresenta características específicas que o afasta dos distúrbios de gênero. Primeiramente, ao contrário do transtorno de identidade sexual, a apotemnofilia ainda não possui suas causas e tratamentos cientificamente determinados ${ }^{11}$ (KONDER, 2003, p. 53). O procedimento aplicado aos casos de transexualidade no Brasil (acompanhamento pessoal por mais de dois anos e cirurgia, caso indicado) é fruto dos estudos e debates realizados pelos profissionais de saúde para aquele distúrbio específico, não havendo sido feito o mesmo trabalho para os casos dos wannabes. Apesar de não haver, em tese, obstáculos para a aplicação do acompanhamento bienal, a realização da cirurgia em seu caráter definitivo é questionável. Isso porque a cirurgia de transgenitalização é permitida por lei em razão da "certeza" do sucesso do tratamento, “certeza” embasada nos já mencionados estudos científicos. Destaque-se que a realização da citada cirurgia é uma exceção à disposição do próprio corpo, e como uma exceção, ela deve ser interpretada restritivamente. Já a apotemnofilia não possui tratamentos testados e comprovados, nem há estudos consistentes sobre esse distúrbio ${ }^{12}$.

Em segundo lugar, embora o tratamento cirúrgico do transtorno de identidade sexual importe em diminuição permanente da integridade física, como na hipótese de retirada do órgão genital masculino, ele não teria o condão de transformar aquele indivíduo em uma pessoa com deficiência ${ }^{13}$ como ocorreria com a cirurgia para a retirada de um membro. Havendo a amputação, o wannabe seria considerado uma pessoa com deficiência e, como tal, estaria sobre o amparo de um sistema protetivo e promocional criado a partir da ratificação da Convenção sobre os Direitos das Pessoas com Deficiência, que possui status de norma constitucional ante a aprovação do Congresso Nacional pelo procedimento previsto no artigo $5^{\circ}, \$ 3^{\circ}$ da CRFB/1988 e trabalhado no plano infraconstitucional pela Lei n. 13.146/2015.

Esse novo sistema é fruto de um processo de reconhecimento social e jurídico de pessoas que nasceram com algum tipo de deficiência ou que em razão de outras circunstâncias da vida se tornaram pessoas com necessidades especiais. A realização da cirurgia amputatória dos apotemnófilos levaria ao paradoxo de se aplicar o mesmo regime jurídico dos deficientes involuntários para aqueles que voluntariamente optaram por se tornar uma pessoa com deficiência. Mesmo que seja possível que o indivíduo com necessidades especiais possa se

\footnotetext{
${ }^{11}$ A apotemnofilia pode ter as mais diversas origens, desde as mais simples, como a visão de uma pessoa amputada na infância, até as mais complexas, como a lesão cerebral (PORRES, RODRIGUES, 2013, p. 39).

${ }^{12}$ María Porres e Ana Rodriguez (2013) afirmam que existe uma tendência de se patologizar comportamentos, e que tratar sofrimentos como doenças dificulta que estes sejam vistos como parte da vida, prejudicando a maneira de se trabalhar os fatores que os causam.

${ }^{13} \mathrm{O}$ artigo $2^{\circ}$ da Lei 13.146/2015, Estatuto da Pessoa com Deficiência, preconiza que a pessoa com deficiência são aquelas que em razão de algum impedimento duradouro, seja intelectual, físico, mental ou sensorial, poderiam ser obstruídas de ter uma participação plena na sociedade.
} 
recusar a fruir dos benefícios provenientes de uma ação afirmativa (art. $4^{\circ} \$ 2^{\circ}$ da Lei n.13.146/2015), aceitar que pessoas com a mesma deficiência, mas que em razão de causas diferentes (voluntárias e involuntárias) fossem tratadas de forma desigual, seria desconsiderar os ganhos sociais conquistados com o advento do microssistema dos direitos da pessoa com deficiência.

María Porres e Ana Rodriguez (2013) criticam o excessivo afã de se preservar a liberdade (ou autonomia) e o desinteresse em se promover a educação para que cada um seja capaz de estabelecer limites adequados e normas razoáveis para sua vida. As autoras afirmam que, hoje em dia, muitos acreditam que seus desejos, por mais estapafúrdios que sejam, podem ser justificados (muitas vezes como distúrbios ou transtornos), devendo a sociedade responder a cada necessidade individual (PORRES, RODRIGUEZ, 2013, p. 41). Deve-se questionar se a realização de cirurgia de amputação em wannabes, mesmo após um período de acompanhamento terapêutico, não seria uma hipótese de supervalorização da autonomia privada.

Deve-se também se atentar para as implicações éticas da conduta dos profissionais de saúde que realizam o procedimento da retirada de um membro saudável para atender aos anseios de um indivíduo. Apesar de a autonomia ser um dos princípios bioéticos, a beneficência e a não maleficência também o são e merecem ser tratados com o mesmo peso. Os profissionais de saúde não podem se "esconder" atrás da autonomia do paciente para se furtarem a ter uma conduta virtuosa, isto é, uma atuação que promova não só um dos princípios, mas sim todos os princípios da bioética.

\section{CONSIDERAÇÕES FINAIS}

Definir os limites existentes entre o exercício da autonomia privada e a proteção/ promoção dos direitos da personalidade é uma tarefa árdua, e as situações que se apresentam no mundo fático tornam tal empreitada ainda mais difícil.

A autonomia privada deve hoje ser compreendida não mais como quase ilimitada e atrelada aos direitos patrimoniais, mas sim, estendida às relações existenciais e sendo concebida pelo seu aspecto relacional.

Os direitos da personalidade, enquanto protetores e promotores do desenvolvimento da personalidade de cada indivíduo, têm que ser vistos como um ganho da sociedade democrática e, portanto, devem ser entendidos como plurais, indo muito além daqueles 
previstos no $\mathrm{CCB} / 2002$. Eles devem ser preservados e a sua disponibilidade deve ser tratada como exceção.

Nesse contexto, a disposição do próprio corpo quando importa diminuição da integridade física é a exceção, devendo esta só ser realizada quando se tratar de uma exigência médica, como no caso do transexualismo, ou no caso de doação de órgãos duplos, como expressamente previsto na Lei de transplantes, não sendo apenas a autonomia privada fundamento para se permitir uma intervenção dessa magnitude.

A apotemnofilia precisa ser estudada para ser compreendida, e a partir de então deve-se buscar tratamentos que permitam que os profissionais da saúde trabalhem com os wannabes, agindo de acordo com todos os princípios bioéticos. Devemos também ter consciência de que tal estudo deve ser acompanhado de perto pelos legisladores para que, quando necessário, sejam elaboradas leis que de fato tragam segurança jurídica e efetividade a tais situações, evitando assim medidas impensadas ou ainda que solucionem apenas parcialmente o problema.

Fato é que, atualmente, nem a área da saúde, nem mesmo a legislação estão preparadas para lidar com a complexa situação dos wannabes, seja por falta de previsão legal efetiva, seja pelo pouco estudo científico da apotemnofilia. 


\section{REFERÊNCIAS BIBLIOGRÁFICAS}

BERTI, Silma Mendes. Fragilização dos Direitos da Personalidade. Revista da Faculdade Mineira de Direito, Belo Horizonte/MG, v. 3, n. 6, 2000. p. 238-248.

BONAVIDES, Paulo. Do estado liberal ao estado social. 8. ed. São Paulo: Malheiros, 2007.

DE CUPIS, Adriano. I diritti della personalitá. Milão: A. Giuffre, 1950.

DINIZ, Maria Helena. O estado atual do biodireito. 8.ed. rev., aum. e atual. São Paulo: Saraiva, 2011.

DIREITOS FUNDAMENTAIS. Existe um direito fundamental de dispor sobre o próprio corpo? Disponível em: < http://direitosfundamentais.net/2008/11/03/existe-umdireito-fundamental-de-dispor-sobre-o-proprio-corpo/>. Acesso em 30 jan. 2014.

FARIA, Roberta Elzy Simiqueli. Autonomia da vontade e autonomia privada uma distinção necessária. IN: FIUZA, César; SÁ, Maria de Fátima Freire de; NAVES, Bruno Torquato de Oliveira (Coord.). Direito civil: atualidades II : da autonomia privada nas situações jurídicas patrimoniais e existenciais. Belo Horizonte: Del Rey, 2007. p. 55-71.

FARIAS, Cristiano Chaves de; ROSENVALD, Nelson. Direito civil: teoria geral. 6. ed. Rio

de Janeiro: Lumen Juris, 2007.

FIÚZA, César. Direito civil: curso completo. 10 ed. Revista, atualizada e ampliada. Belo Horizonte: Del Rey, 2007.

GAGLIANO, Pablo Stolze; PAMPLONA FILHO, Rodolfo. Novo curso de direito civil: volume 1: parte geral. 13. ed. São Paulo: Saraiva, 2011.

GOMES, Frederico Barbosa. As contribuições de Kant, de Rousseau e de Habermas para o estudo da autonomia no âmbito do direito. In: FIUZA, César; SÁ, Maria de Fátima Freire de; NAVES, Bruno Torquato de Oliveira (Coord.). Direito civil: atualidades II : da autonomia privada nas situações jurídicas patrimoniais e existenciais. Belo Horizonte: Del Rey, 2007. p.25-54.

JABUR, Gilberto Haddad. Breve leitura dos Direitos da Personalidade. In: FILOMENO, José Geraldo Brito; WAGNER JUNIOR, Luiz Guilherme da Costa; GONÇALVES, Renato Afonso (Coord.) O Código Civil e a sua interdisciplinariedade: os reflexos do Código Civil nos demais ramos do Direito. Belo Horizonte-MG: Del Rey, 2004.p. 400419.

KANT, Immanuel. Fundamentação da metafísica dos costumes. Trad. de Paulo Quintela. 
Lisboa: Edições 70, 1995.

KONDER, Carlos Nelson. Consentimento no biodireito. Os casos dos transexuais e dos wannabes. Revista Trimestral de Direito Civil - RTDC, vol. 15, p. 41-71. Jul./set. 2003.

LOCH, Jussara de Azambuja. Princípios da Bioética. In: KIPPER DJ. (editor) Uma Introdução à Bioética. Temas de Pediatria Nestlé, n.73, 2002. p. 12-19

MATIELLO, Fabrício Zamprogna. Código Civil Comentado. São Paulo: LTr, 2003.

MENEZES, Joyceane Bezerra de; GONÇALVES, Camila Figueiredo Oliveira.A Construção da identidade e os atos de disposição do próprio corpo. In: XXI Congresso Nacional do CONPEDI / UFF, 2012, Niterói. Anais do XXI Congresso nacional do CONPEDI / UFF. Florianópolis - SC: Fundação Boiteux, 2012. p.35/54.

NAVES, Bruno Torquato de Oliveira; REZENDE, Danúbia Ferreira Coelho. Autonomia Privada do paciente terminal. In: FIUZA, César; NAVES, Bruno Torquato de Oliveira; SÁ, Maria de Fátima de. Direito civil: atualidades II. Belo Horizonte: Del Rey: 2007. p. 75-88.

ORGANIZAÇÃO MUNDIAL DE SAÚDE. http://www.direitoshumanos.usp.br/index.php/OMS-Organiza\%C3\%A7\%C3\%A3oMundial-da-Sa\%C3\%BAde/constituicao-da-organizacao-mundial-da-saude-omswho.html. Acesso em 16/07/2015.

PENALVA, Luciana Dadalto. Declaração prévia de vontade do paciente terminal. Dissertação (Mestrado em Direito Privado) - Pontifícia Universidade Católica de Minas Gerais, Belo Horizonte. 2009.

PORRES, María Diéguez; RODRÍGUEZ, Ana González. La falta como ideal. Apotemnofilia o la integridad es no estar completo. Átopos: Salud mental, comunidad y cultura. n. 4, p. 38-43. Set. 2013.

SÁ, Maria de Fátima Freire de; NAVES, Bruno Torquato de Oliveira. Manual de Biodireito.

Belo Horizonte: Del Rey, 2011.

SARLET, Ingo Wolfgang; MARINONI, Luiz Guilherme; MITIDIERO, Daniel. Curso de direito constitucional. São Paulo: Revista dos Tribunais, 2012.

VIEIRA, Marcelo de Mello. Testamento vital no Direito Brasileiro: realidade ou perspectiva

para o futuro?. In: XXI Encontro nacional do CONPEDI / UFF, 2012, Niterói. Anais do XXI do Congresso do CONPEDI / UFF. Florianópolis - SC: Fundação Boiteux, 2012. p.35-54. 